ORIGINAL PAPER

\title{
The prognostic significance of ANDROgEN RECEPTOR AND $\beta$-CATENIN IMMUNOHISTOCHEMICAL EXPRESSION IN UROTHELIAL CARCINOMA WITH AND WITHOUT DETRUSOR MUSCLE INVASION FROM AN EGYPTIAN INSTITUTION
}

\author{
Shaimaa Elzamy ${ }^{1}$, Abd Allah MS ${ }^{1}$, Wael Kandeel ${ }^{2}$
}

${ }^{1}$ Pathology Department, Faculty of Medicine, Benha University, Egypt

${ }^{2}$ Urology Department, Faculty of Medicine, Benha University, Egypt

\begin{abstract}
Androgen receptor (AR) activation plays an important role in the promotion and progression of urothelial tumorigenesis. Also, dysregulation of the $\mathrm{Wnt} / \beta$-catenin signaling pathway has also been linked to bladder cancer growth. However, cross talk between the two pathways in remains unclear in bladder cancer. This study investigated the prognostic significance of $A R$ and $\beta$-catenin expression and their relationship to different clinic-pathological parameters, recurrence free and progression free survival.

106 urothelial carcinoma cases were used to study the immunohistochemical expression of AR and $\beta$-catenin. Log-Rank test to compare survival between groups. Androgen receptor positivity was in $37(34.9 \%)$ cases. Both aberrant $\beta$-catenin and $A R$ positivity were associated with higher tumor grade $(p=0.033$ and $p=0.037$ respectively) and muscle invasion $(\mathrm{p}=0.007$ and $\mathrm{p}=0.039$ respectively). Aberrant $\beta$-catenin only showed statistically significant association with tumor diameter $(p=0.036)$, tumor stage $(p=0.038)$, LN metastasis $(p=0.001)$, tumor recurrence $(\mathrm{p}=0.026)$ and tumor progression $(\mathrm{p}=0.01)$. Cases with aberrant $\beta$-catenin showed higher AR positivity ( $\mathrm{p}=0.018)$.

Our study highlighted important information about the link between Wnt/ $\beta$-catenin and AR pathway during the progression of transitional urothelial carcinoma with aberrant $\beta$-catenin could be used as a prognostic marker
\end{abstract}

Key words: androgen receptors, $\beta$-catenin, non-detrusor muscle invasive urothelial carcinoma, detrusor muscle invasive urothelial carcinoma.

\section{Introduction}

Urinary bladder cancer is ranked the ninth most common cancer worldwide. It is considered the fourth among males, the ninth among females and the second of genitourinary cancers $[1,2,3,4]$. One important feature is that the incidence is three to four times higher in male patients than in females, while females present with more aggressive cancers than males [3, 4]. In Egypt, in males, urinary bladder cancer accounts for $17 \%$ of all cancer cases while in females it is $5 \%$. The male to female ratio is $3.5: 1[5,6]$. Urinary bladder cancer is tightly linked to smoking [7], to the exposure to industrial carcinogens and chronic Schistosoma cystitis [8]. However, These risk factors are not enough to explain the wide gender difference [9]. Hormonal factors are considered as an explanation 
Table I. Clinicopathological variables of the studied cases

\begin{tabular}{|c|c|c|c|}
\hline \multicolumn{2}{|c|}{ CLINIC PATHOLOGICAL DATA } & \multirow{2}{*}{$\begin{array}{c}\begin{array}{c}\text { Number } \\
(\mathrm{N}=106)\end{array} \\
59.5 \pm 8.8\end{array}$} & \multirow{2}{*}{$\begin{array}{c}\% \\
(100 \%) \\
(36-72)\end{array}$} \\
\hline Age (years) & $\begin{array}{l}\text { Mean } \pm \text { SD } \\
\text { (Range) }\end{array}$ & & \\
\hline & $\geq 50$ & 84 & 79.2 \\
\hline & $<50$ & 22 & 20.8 \\
\hline \multirow[t]{2}{*}{ Gender } & Male & 83 & 78.3 \\
\hline & Female & 23 & 21.7 \\
\hline \multirow[t]{2}{*}{ Bilharziasis } & Negative & 75 & 70.8 \\
\hline & Positive & 31 & 29.2 \\
\hline \multirow[t]{3}{*}{$\begin{array}{l}\text { Tumor } \\
\text { diameter }\end{array}$} & $\begin{array}{l}\text { Mean } \pm \text { SD } \\
\text { (Range) }\end{array}$ & \multicolumn{2}{|c|}{$3.9 \pm 1.4(1.8-8.0)$} \\
\hline & $\leq 3 \mathrm{~cm}$ & 41 & 38.7 \\
\hline & $>3 \mathrm{~cm}$ & 65 & 61.3 \\
\hline \multirow[t]{6}{*}{ Tumor stage } & Tis(CIS) & 6 & 5.7 \\
\hline & $\mathrm{Ta}$ & 5 & 4.7 \\
\hline & $\mathrm{T} 1$ & 16 & 15.1 \\
\hline & $\mathrm{T} 2$ & 32 & 30.2 \\
\hline & $\mathrm{T} 3$ & 39 & 36.8 \\
\hline & $\mathrm{T} 4$ & 8 & 7.5 \\
\hline \multirow[t]{2}{*}{$\begin{array}{l}\text { Muscle } \\
\text { invasion }\end{array}$} & $\begin{array}{c}\text { Non muscle } \\
\text { invasive tumors }\end{array}$ & 27 & 25.5 \\
\hline & $\begin{array}{l}\text { Muscle invasive } \\
\text { tumors }\end{array}$ & 79 & 74.5 \\
\hline \multirow[t]{4}{*}{ Lymph node } & No & 44 & 41.5 \\
\hline & N1 & 42 & 39.6 \\
\hline & $\mathrm{N} 2$ & 14 & 13.2 \\
\hline & N3 & 6 & 5.7 \\
\hline \multirow{2}{*}{$\begin{array}{l}\text { Distant } \\
\text { metastasis }\end{array}$} & M0 & 99 & 93.4 \\
\hline & M1 & 7 & 6.6 \\
\hline \multirow[t]{3}{*}{ Grade } & PUNLMP & 8 & 7.5 \\
\hline & Low grade & 40 & 37.7 \\
\hline & High-grade & 58 & 54.7 \\
\hline \multirow[t]{2}{*}{ Recurrence } & Negative & 79 & 74.5 \\
\hline & Positive & 27 & 25.5 \\
\hline \multirow[t]{2}{*}{ Progression } & Negative & 90 & 84.9 \\
\hline & Positive & 16 & 15.1 \\
\hline
\end{tabular}

of such difference nowadays depending on observations from animal studies. N-butyl-N-(4-hydroxybutyle) nitrosamine-induced bladder cancers more frequently and more rapidly in males than in females in animal studies [7]. In addition, the observation that post-menopausal women develop more bladder cancer than premenopausal supports the importance of the hormonal factors [10].
Although the involvement of androgen receptor (AR) in urinary bladder carcinogenesis has been revealed in several studies, there are studies with conflicting results about the role of AR expression in bladder cancer progression.

Intracellular molecular pathways are usually connected. Cross talks between the WNT/ $\beta$-catenin pathway and the androgen/androgen receptor pathway had been reported particularly in prostatic cancer $[11,12,13]$. The WNT/ $\beta$-catenin pathway has a fundamental role in cell proliferation, migration, polarity, and maintenance of stem cells. The abnormal activation of WNT/ $\beta$-catenin pathway itself has been implicated in many cancer types especially in the epithelia arising from an endodermal origin such as prostate and colon [14]. In mice, the WNT/ $\beta$-catenin signaling is essential for urothelial basal cells regeneration after injury [15]. Also, the forced expression of constitutively activated forms induces urothelial overgrowth. These observations highlight the role of the $\mathrm{WNT} / \beta$-catenin pathway in the urothelial carcinogenesis $[14,16]$.

The interaction between $\mathrm{AR}$ and $\beta$-catenin proteins in bladder cancer cell lines has been reported recently. This made us interested in further evaluating immunohistochemical expression of $\mathrm{AR}$ and $\beta$-catenin proteins in bladder cancer. We are investigating their relationship with different clinic-pathological features and prognostic significance in a unique study population. The patients in this study are from a rural area in Egypt where schistosomiasis is endemic.

\section{Material and methods}

This is a retrospective case-control study approved by the institutional review board of Faculty of Medicine, Benha University, Egypt. A total of 106 archived specimen of only transitional urothelial carcinoma, was included in the study. Fifteen normal urothelium from patients with benign prostatic hyperplasia were used as control group. Paraffin blocks were from the Pathology Department, Faculty of Medicine, Benha University. Patients who received intravesical bacilli Calmette-Guerin (BCG), chemotherapy, radiotherapy, or hormonal therapy before cystectomy was excluded from the study. Recurrence-free survival (RFS) and progression-free survival (PFS) were calculated over a 36-month period.

\section{Histopathological examination of the cases}

The hematoxylin and eosin sections of the selected cases were reviewed. Cases were graded according to the WHO/International Society of Urological Pathology 2004, into low-grade urothelial carcinoma, and high-grade urothelial carcinoma. Cases were staged according to the American Joint Committee on Cancer 
(AJCC), 2002 and were grouped into non-Detrusor muscle (non-DM) invasive (superficial) and Detrusor muscle-invasive (DM) tumors. The non-DM invasive group included the cases of carcinoma in situ, $\mathrm{pTa}$ and $\mathrm{pT} 1$. The DM-invasive group included the cases of pT2, pT3, and PT4. Clinical data including age, gender, were identified. Histopathological features including, the grade, the tumor stage, lymph node involvement, distant metastasis, the tumor diameter, the presence of bilharzial ova or granulomas, were all included in the study. The clinicopathological data are listed in Table I.

\section{Immunohistochemistry}

The tissue expression of both $\mathrm{AR}$ and $\beta$-catenin was performed using the streptavidin-biotin immunoperoxidase technique described by Hsu et al. [17] Two tissue sections, $5 \mathrm{~mm}$ each were cut from preselected representative formalin-fixed, paraffin embedded tissue blocks. Sections were deparaffinized in xylene and rehydrated in a graded series of ethanol. The endogenous peroxidase was blocked using $0.5 \%$ solution of hydrogen peroxide. Antigen retrieval was done by boiling the slides in $0.01 \mathrm{M}$ citrate buffer solution, PH 6.0 using the microwave. Slides were then incubated overnight at $4^{\circ} \mathrm{C}$ with primary Monoclonal Mouse Anti-Human AR antibody clone AR441 (Dako, USA) diluted 1 : 50 in PBS and Monoclonal Mouse Anti-Human $\beta$-catenin antibody (Dako, USA) diluted 1 : 100 in PBS. After washing and adding the secondary antibody, diaminobenzidine was applied, and Meyer hematoxylin was used for counterstaining. Benign prostatic tissue was used as a positive control. The negative control was performed without incubating the tissue slides with the primary antibody.

\section{The scoring of $A R$ and $\beta$-catenin stain}

Two pathologists SE and MS scored the immunohistochemical expression of $\mathrm{AR}$ and $\beta$-catenin protein semiquantitative way and were double blinded. Scoring was following previous studies. The expression of AR was nuclear, while for $\beta$-catenin; membranous or nuclear or cytoplasmic. The percent of positive nuclei is calculated in relation to the total tumor nuclei. The tumor is considered positive if $>10 \%$ of the tumor nuclei were showing positive AR stains [18]. While for the $\beta$-catenin the tumor is considered positive if $>70 \%$ of the tumor shows a membranous stain. $\beta$-catenin showed either normal membranous expression or aberrant expression if it was nuclear or cytoplasmic [15]. The immunohistochemical scoring and histopathological evaluation were performed by the two pathologists independently and blinded.

\section{Statistical analysis}

The collected data were tabulated and analyzed using SPSS version 16 software (SPSS Inc, Chicago, ILL Company). Categorical data were presented as number and percentages using chi-square $\left(\chi^{2}\right)$ test or Fisher's exact test (FET) for their analysis, while quantitative data were expressed as a mean \pm standard deviation, median, and range. Quantitative data were tested for normality using Shapiro Wilks test assuming normality at $\mathrm{p}>0.05$, using t Student test to analyze parametric variables. Kaplan Meier curve was used to determine survival probability among the patients according to the levels of the studied markers. Log-Rank test was used to compare survival between groups. The accepted level of significance in this work was stated at 0.05 $(\mathrm{p}<0.05)$ was considered significant. Recurrence was defined as a recurrent bladder cancer that is confirmed histologically after the initial TUR. Progression is defined as recurrent cancer that invades into the muscle layer. And accordingly; the recurrence-free survival (RFS) and progression-free survival (PFS) was calculated as the time from the initial TUR to the occurrence of recurrence and progression respectively. After cystectomy; RFS is calculated from the date of cystectomy to the first documented local recurrence.

\section{Results}

\section{Patient demographics and clinicopathologic findings}

This retrospective study included 106 of histopathologically confirmed cases of transitional urothelial carcinomas. The mean age was $59.5 \pm 8.8$. All clinicopathologic data were summarized in Table I.

\section{Immunohistochemical results}

\section{Analysis of AR immunostaining}

Nuclear AR expression in urothelial carcinoma cases was positive in $34.9 \%(n=37)$ cases while $65.1 \%$ ( $\mathrm{n}=69)$ were negative. Out of 15 non-neoplastic control cases, none of the cases $(0 \%)$ showed positive AR expression. AR expression level in bladder carcinoma was significantly higher than non-neoplastic tissue $(\mathrm{p}=0.006)$.

In the study group (83 males and 23 females) only 37 cases (29 males and eight females) expressed AR. No statistically significant difference was observed between AR expression in men and women of our study $(\mathrm{p}=0.99)$.

A statistically significant positive association was detected between positive AR expression and tumor grade $(\mathrm{p}=0.037)$. Positive AR expression showed a positive association with muscle invasion $(p=0.039)$. Positive AR expression did not show any significant association with other clinicopathologic parameters as detailed in Table II. 

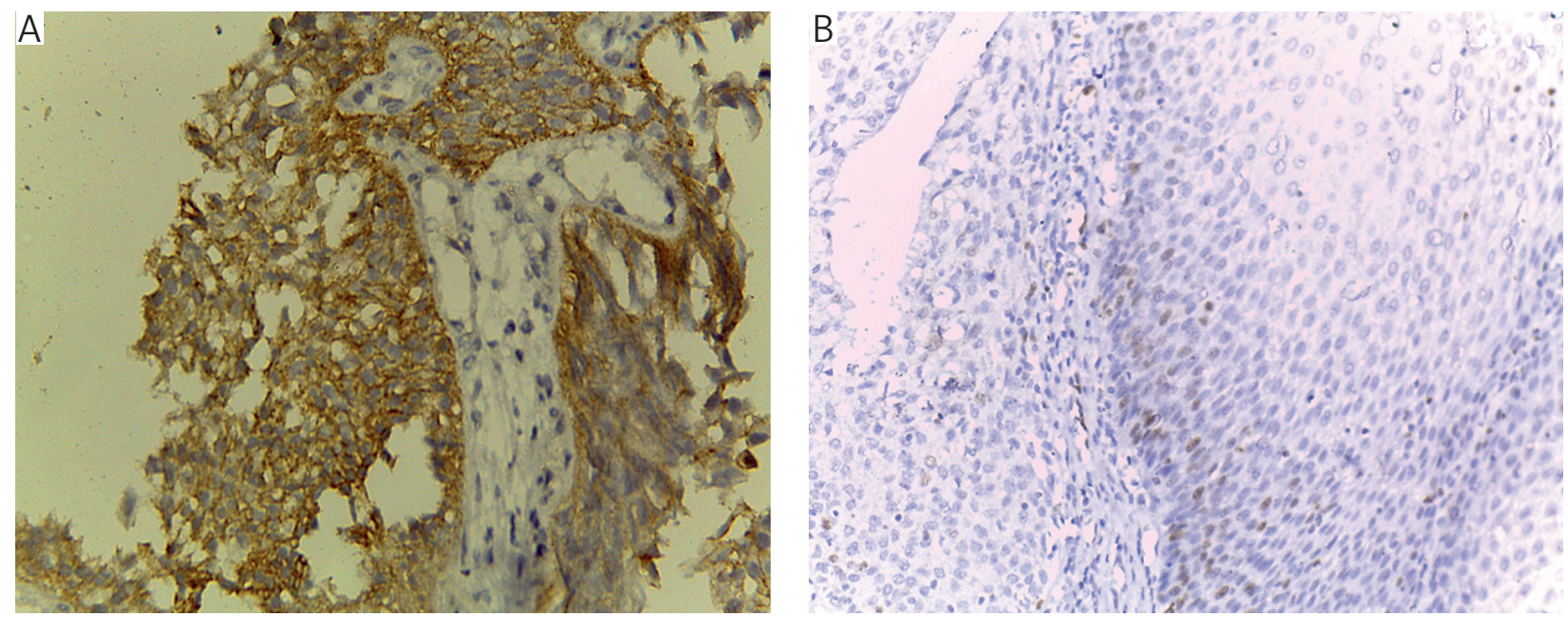

Fig. 1. Immunohistochemical staining of $\beta$-catenin and AR in non-detrusor muscle invasive urothelial carcinoma. A) $\beta$-catenin with membranous expression $(100 \times)$. B) AR minimal expression $(100 \times)$
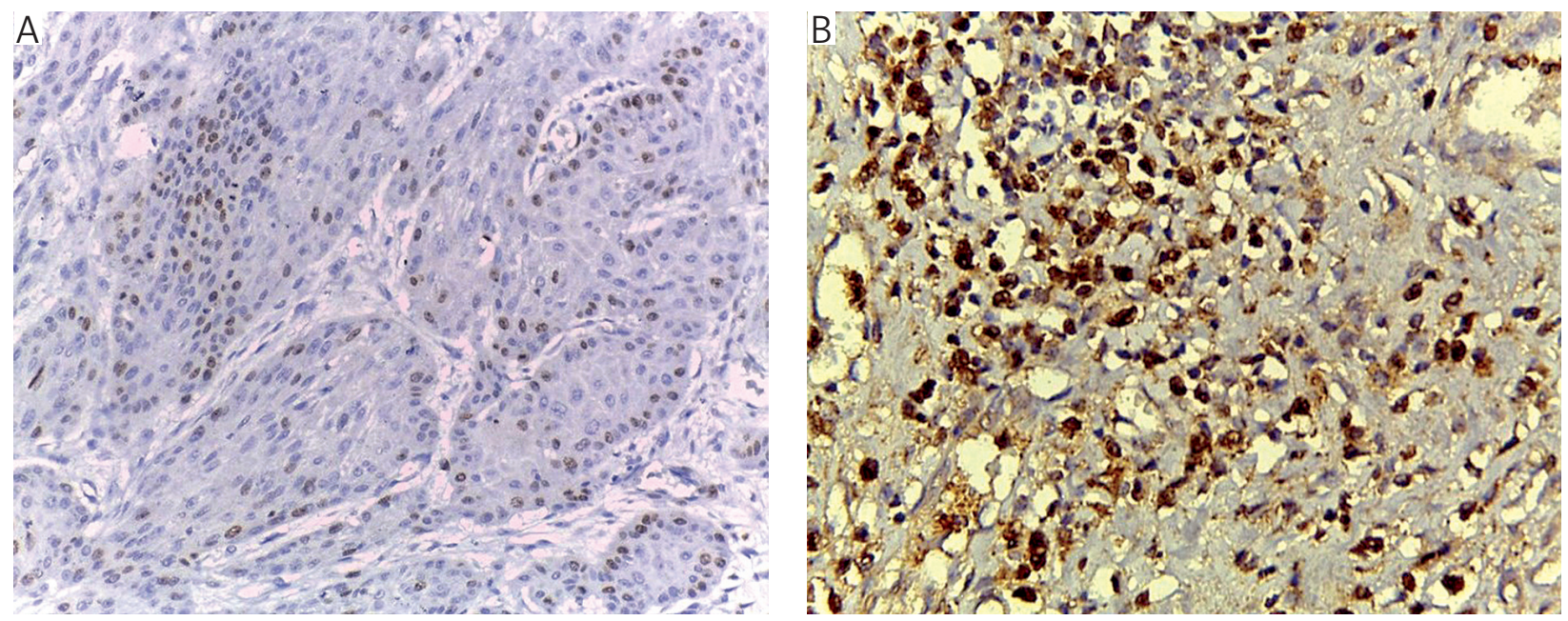

Fig. 2. Immunohistochemical nuclear expression of AR in non-detrusor muscle invasive urothelial carcinoma: A) shows low expression $(100 \times)$; B) shows high expression $(200 \times)$
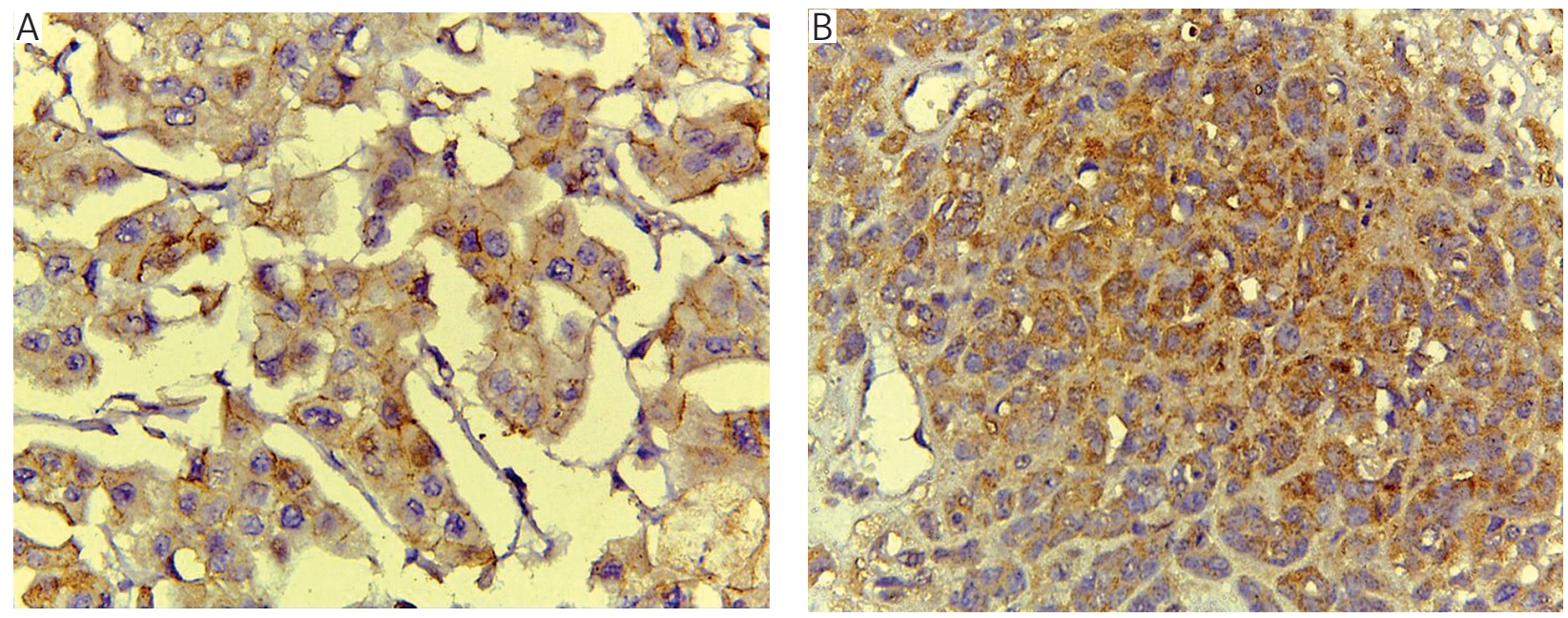

Fig. 3. Immunohistochemical nuclear expression of aberrant $\beta$-catenin in non-detrusor muscle invasive urothelial carcinoma: A) Tumour cells still show some membranous staining with aberrant cytoplasmic expression $(400 \times)$; B) loss of all membranous staining with aberrant cytoplasmic expression $(400 \times)$ 
Table II. The distribution and comparison of AR and aberrant $\beta$-catenin according to the clinicopathological variables

\begin{tabular}{|c|c|c|c|c|c|c|c|}
\hline \multirow{3}{*}{$\begin{array}{l}\text { CLINICOPATHOLOGICAL } \\
\text { VARIABLES }\end{array}$} & & \multicolumn{3}{|c|}{ AR } & \multicolumn{3}{|c|}{ ABERRANT $\beta$-CATENIN } \\
\hline & \multicolumn{2}{|l|}{ Positive } & \multirow[t]{2}{*}{$\mathrm{P}$} & \multicolumn{2}{|c|}{ POSITIVE } & \multirow[t]{2}{*}{$\mathrm{P}$} & \\
\hline & No & $\%$ & & No & $\%$ & & \\
\hline \multirow[t]{3}{*}{ Age } & $<50(\mathrm{n}=22)$ & 7 & 31.8 & \multirow[t]{3}{*}{0.91} & 12 & 54.5 & \multirow[t]{3}{*}{0.6} \\
\hline & $\geq 50(n=84)$ & 30 & 35.7 & & 43 & 51.2 & \\
\hline & $($ mean $\pm \mathrm{SD})$ & \multicolumn{2}{|c|}{$59.3 \pm 8.7$} & & \multicolumn{2}{|c|}{$58.7 \pm 9.1$} & \\
\hline \multirow[t]{2}{*}{ Gender } & Male $(n=83)$ & 29 & 34.9 & \multirow[t]{2}{*}{0.99} & 44 & 53 & \multirow[t]{2}{*}{0.66} \\
\hline & Female $(\mathrm{n}=23)$ & 8 & 34.8 & & 11 & 47.8 & \\
\hline \multirow[t]{2}{*}{ Billharziasis } & Positive $(\mathrm{n}=31)$ & 10 & 32.3 & \multirow[t]{2}{*}{0.71} & 15 & 48.4 & \multirow[t]{2}{*}{0.64} \\
\hline & Negative $(\mathrm{n}=75)$ & 27 & 36 & & 40 & 53.3 & \\
\hline \multirow[t]{3}{*}{ Tumor Diameter } & $\leq 3 \mathrm{~cm}(\mathrm{n}=41)$ & 15 & 36.6 & \multirow[t]{3}{*}{0.11} & 16 & 39 & \multirow[t]{3}{*}{$0.036 *$} \\
\hline & $>3 \mathrm{~cm}(\mathrm{n}=65)$ & 22 & 33.8 & & 39 & 60 & \\
\hline & $($ mean $\pm \mathrm{SD})$ & \multicolumn{2}{|c|}{$3.64 \pm 1.2$} & & \multicolumn{2}{|c|}{$4.1 \pm 1.5$} & \\
\hline \multirow[t]{6}{*}{ Tumor Stage } & $\operatorname{Tis}(\mathrm{CIS})(\mathrm{n}=6)$ & 1 & 16.7 & \multirow[t]{6}{*}{0.97} & 1 & 16.7 & \multirow[t]{6}{*}{$0.038 *$} \\
\hline & $\mathrm{Ta}(\mathrm{n}=5)$ & 1 & 20.0 & & 2 & 40.0 & \\
\hline & $\mathrm{T} 1(\mathrm{n}=16)$ & 3 & 18.8 & & 3 & 18.8 & \\
\hline & $\mathrm{T} 2(\mathrm{n}=32)$ & 11 & 34.4 & & 10 & 31.2 & \\
\hline & T3 $(\mathrm{n}=39)$ & 19 & 48.7 & & 31 & 79.5 & \\
\hline & $\mathrm{T} 4(\mathrm{n}=8)$ & 2 & 25.0 & & 8 & 100.0 & \\
\hline \multirow[t]{2}{*}{ Muscle invasion } & $\begin{array}{c}\text { Non-muscle } \\
\text { invasive }(n=27)\end{array}$ & 5 & 18.5 & \multirow[t]{2}{*}{$0.039 *$} & 8 & 29.6 & $0.007 * *$ \\
\hline & $\begin{array}{l}\text { Muscle invasive } \\
(\mathrm{n}=79)\end{array}$ & 32 & 40.5 & & 47 & 59.5 & \\
\hline Lymph node & N0 $(n=44)$ & 12 & 27.3 & 0.16 & 10 & 22.7 & $0.001 * *$ \\
\hline Metastasis & $\mathrm{N} 1(\mathrm{n}=42)$ & 20 & 47.6 & & 29 & 69 & \\
\hline & $\mathrm{N} 2(\mathrm{n}=14)$ & 3 & 21.4 & & 11 & 78.6 & \\
\hline & N3 $(n=6)$ & 2 & 33.3 & & 5 & 83.3 & \\
\hline Distant Metastasis & M0 (n = 99) & 35 & 35.4 & 1.0 & 50 & 50.5 & 0.44 \\
\hline & $\mathrm{M} 1(\mathrm{n}=7)$ & 2 & 28.6 & & 5 & 71.4 & \\
\hline Grade & PUNLMP $(\mathrm{n}=8)$ & 1 & 12.5 & $0.037 *$ & 1 & $12.5 \%$ & $0.033^{*}$ \\
\hline & Low $(n=40)$ & 6 & 15.0 & & 11 & 27.5 & \\
\hline & $\operatorname{High}(\mathrm{n}=58)$ & 30 & 51.7 & & 43 & $74.1 \%$ & \\
\hline Recurrence & Abscent $(\mathrm{n}=79)$ & 25 & 31.6 & 0.23 & 36 & 45.6 & $0.026 *$ \\
\hline & Positive $(\mathrm{n}=27)$ & 12 & 44.4 & & 19 & 70.1 & \\
\hline Progression & Abscent $(\mathrm{n}=90)$ & 30 & 33.3 & 0.42 & 42 & 46.7 & $0.01 *$ \\
\hline & Positive $(\mathrm{n}=16)$ & 7 & 43.8 & & 13 & 81.2 & \\
\hline Total & & $37 / 106$ & 34.9 & & $55 / 106$ & 51.9 & \\
\hline
\end{tabular}

\section{Analysis of $\beta$-catenin immunostaining}

Aberrant cytoplasmic $\beta$-catenin expression was positive in $51.9 \%(\mathrm{n}=55)$ of bladder carcinoma cases while $48.1 \%(n=51)$ were negative with medi- an expression 15.0. All non-neoplastic control cases were negative for aberrant $\beta$-catenin confirming high significant association in its expression in TCC than non-neoplastic urothelium ( $<<0.001)$. 
A

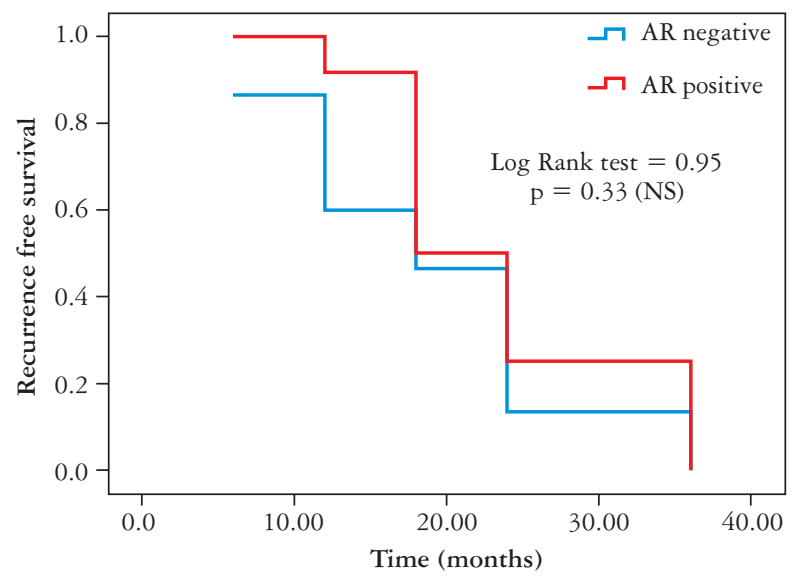

B

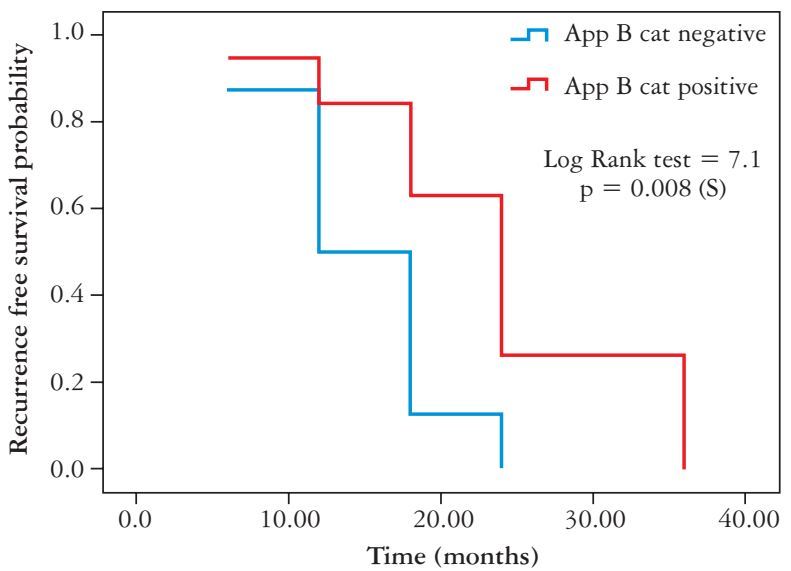

Fig. 4. Kaplan-Meier curve for reccurence free survival according to AR expression (A) and aberrant $\beta$-catenin expression (B)

A

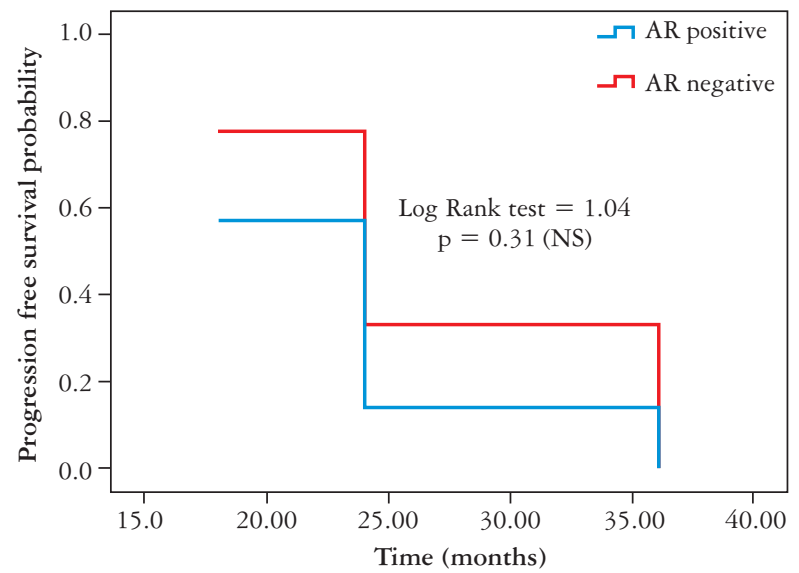

B

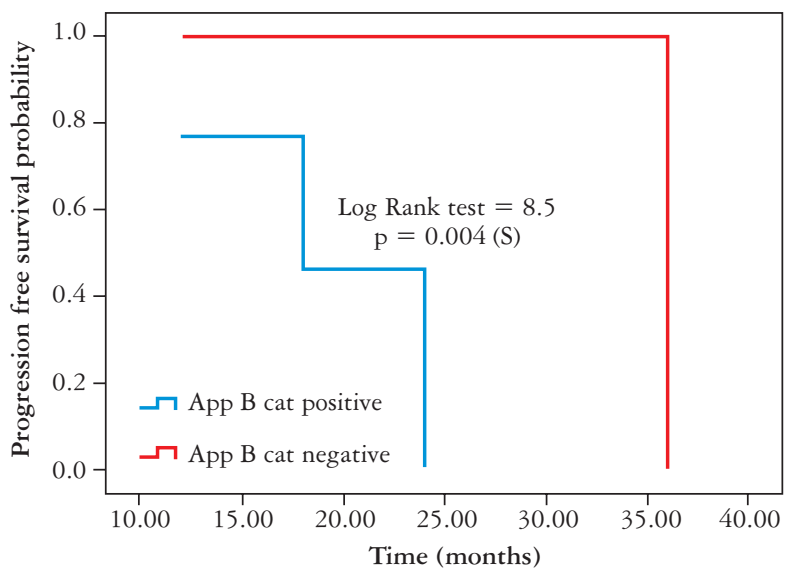

Fig. 5. Kaplan-Meier curve for progression free survival according to AR expression (A) and aberrant $\beta$-catenin expression (B)

Normal membranous $\beta$-catenin was detected in $50.9 \%(\mathrm{n}=54)$ of bladder carcinoma cases and $93.3 \%(\mathrm{n}=14)$ of non-neoplastic control cases confirming significant association in its expression in non-neoplastic urothelium than TCC ( $\mathrm{p}<0.001)$.

Positive aberrant $\beta$-catenin expression showed statistically significant association with tumor diameter $(\mathrm{p}=0.036)$, tumor grade $(\mathrm{p}=0.033)$, tumor stage $(\mathrm{p}=0.038)$, muscle invasion ( $\mathrm{p}=0.007), \mathrm{LN}$ metastasis $(\mathrm{p}=0.001)$, tumor recurrence $(\mathrm{p}=0.026)$ and tumor progression $(\mathrm{p}=0.010)$ as detailed in Table II.

\section{Correlation between $A R$ expression and aberrant $\beta$-catenin}

The present study demonstrated a significant association between AR expression and aberrant $\beta$-catenin $(\mathrm{p}=0.018)$. Among 55 cases that were positive for aberrant cytoplasmic $\beta$-catenin, 25 cases (45.5\%) were positive for $\mathrm{AR}$ while 30 cases $(54.5 \%)$ were negative. This is summarized in Table III.

\section{Kaplan-Meier analysis}

The recurrence-free survival probability and the progression-free survival likelihood of cases with negative Aberrant cytoplasmic $\beta$-catenin were significantly higher than cases with positive aberrant $\beta$-catenin ( $\mathrm{p}=0.008 ; \mathrm{p}=0.004)$ respectively. The recurrence-free survival probability and the progression-free survival probability of patients showed no significant association with AR expression $(\mathrm{p}=0.33)$ and $(\mathrm{p}=0.31)$, respectively.

On multivariable analysis, muscle invasion $(\mathrm{p}=0.001 ; 95 \% \mathrm{CI}: 0.258-0.670)$, higher grade $(\mathrm{p}=0.038$; 95\% CI: 0.010-0.334), aberrant $\beta$-catenin $(\mathrm{p}=0.008$; 95\% CI: 0.065-0.413) were significantly associated with recurrence rates. In the progression rate analysis, pathologic tumor stage $(\mathrm{p}=0.012 ; 95 \% \mathrm{CI}: 0.019-0.147)$ and aberrant $\beta$-catenin ( $p=0.001 ; 95 \% \mathrm{CI}: 0.002-0.008)$ were significantly associated with progression rates. 
Table III. The association between AR and aberrant $\beta$-catenin

\begin{tabular}{llccc}
\hline Aberrant & & $\mathbf{N}$ & \multicolumn{2}{c}{ AR expression } \\
\cline { 3 - 4 }$\beta$-Catenin & & & Negative & Positive \\
\cline { 3 - 4 } & & & $\mathbf{N}(\%)$ & $\mathbf{N}(\%)$ \\
\cline { 2 - 4 } & Negative & 51 & $39(76.5)$ & $12(23.5)$ \\
\cline { 2 - 4 } & Positive & 55 & $30(54.5)$ & $25(45.5)$ \\
\cline { 2 - 4 } & Total & 106 & $69(65.1)$ & $37(34.9)$ \\
\hline \multicolumn{3}{c}{$\mathrm{p}=0.018^{*}$} \\
\hline
\end{tabular}

\section{Discussion}

Urinary bladder transitional cell carcinoma is relatively common in urology clinical practice. In Egypt, until recent years, urinary bladder cancer was the most frequently diagnosed cancer due to Schistosoma haematobium [8]. The incidence of urothelial carcinoma in males is three to four times more than in females $[3,4]$ this is also observed in animal studies [19, 20]. Environmental factors such as smoking and industrial hazards are not enough to explain such difference [21]. Hormonal factors especially androgens and their receptors are now blamed to be a reason for such difference [22]. On the molecular level, the intracellular pathways are frequently interconnected. An example for this is the Wnt/ $\beta$-catenin and AR pathways. In the present study, we examined the relationship between AR and $\beta$-catenin expression and different clinicopathological parameters and prognosis in patients with TCC.

The urinary bladder originates from the urogenital sinus like the accessory sex organs which include (seminal vesicles, prostate, and bulbourethral glands). This embryological origin may explain the potential of the urinary bladder to respond to androgen signals which are mediated by androgen receptors [23]. When testosterone enters the cell, it either binds to AR directly or after its conversion to $5 \alpha$-dihydrotestosterone by $5 \alpha$-reductase [24]. Androgen receptors are present in the cytoplasm, but upon binding to androgen, the androgen-AR complex translocates into the nucleus, leading to transcriptional activity [25]. This is supported by several in vitro studies that assessed the effect of androgens and androgen receptors on the urinary bladder cancer cells [26]. These studies concluded that androgen increases the AR-responsive reporter gene activity. Also, the AR expression can be altered by treating the cells with androgens or androgen antagonist [24].

In our study, there was a positive nuclear expression of AR in $34.9 \%$ of TCC cases while none of the normal tissue expressed AR. This is matching the results of Mashhadi et al. [27], Tuygun et al. [28], and Ruizeveld de Winter [29] Boorjian et al. [30] and Birtle et al. [22] who all failed to show higher expression of AR in benign tissue in relation to the cancer tissue. This is in contrast to the study done by Kauffman et al. [31] Miyamoto et al. [32] and Kirkali et al. [29], where loss of AR expression in malignant tissue was reported, and accordingly, they concluded that AR did not have a direct role in malignant transformation. Also against Kashiwagi et al. [33] who showed less frequent expression of AR in malignant tissue in relation to normal tissue.

The relation between AR expression and the different clinicopathological parameters is controversial. Our results showed that AR expression is significantly associated with the high grade of the tumor $(p=0.037)$. This is matching the results of Mashhadi et al. [27] who concluded that among steroid hormone receptors, only AR expression had a significant association with the stage and grade of the tumor. This is in contrast with Li et al. [24] who concluded that AR expression is decreased with high grade and stage of the tumor. Also against the results of Boorjian et al. [30], Tuygun et al. [28]. However, in a large study by Mir [34], there was no statistical difference between high and low-grade tumors.

Our results showed no significant association with the stage of the tumor and this is going with the results of Mir et al. [34] and Zhaung [35]. While the results of Boorjian et al. [23] showed that loss of $\mathrm{AR}$ expression is associated with advanced stage of the tumor, suggesting that the loss of AR may play a role in invasive cancer. While in the study of Mashhadi et al. [27] they found a significant association between AR expression and the stage of the tumor. Kashiwagi et al. [33], found no significant association between steroid hormone receptors and the histopathological characteristics of the tumor including the grade, stage.

Based on that, the role of AR expression as a prognostic tool is controversial. Our study did not find a significant association between AR expression and either the RFS or PFS. This is matching the results of Mir et al. [34] where there was no statistically significant difference between death from bladder cancer, time to death or time to recurrence between AR-positive and AR-negative cases. Also, Kashiwagi et al. [33] found that AR expression has no prognostic significance. Also, the study of Tuygun et al. [28] that included 139 cases of bladder carcinoma showed that AR expression did not have any influence on the RFS or PFS. Accordingly, they concluded that AR expression does not have prognostic significance. In contrast, the study of Mishhadi et al. [27] found that cases with positive AR expression have a poor prognosis. In a pilot study using 33 cases of superficial bladder cancer found that AR-positive cases had higher recurrence rate [36]. Miyamoto et al. [32] indicated that loss of AR in bladder cancer is a predictor of worse prognosis. On the other side, our results showed that there was more AR expression in 
muscle-invasive tumors in contrast to non-muscle invasive tumors $(\mathrm{p}=0.039)$. And this is matching the results of the large study done by Mir et al. [34]. Our study showed that AR expression is not gender related and this is matching almost all studies that are done $[23,28,31,32,34,35,37]$. To our knowledge, only one study [23] expression was decreased more in female patients. In vitro studies showed that the presence of Schistosoma haematobium parasite extracts were able to induce cancer like phenotypes such as apoptosis, proliferation, invasion, and migration [38]. This might be due to the estrogenic molecules that were found to be present in both parasite extract and in patient's sera and were able to suppress the transcriptional activity and have a potential effect on the dysregulation of tumor suppressor gene p53 [39]. However, in our study, the presence of schistosomiasis did not have any statistically significant association with the AR expression.

Regarding the expression of $\beta$-catenin, our study showed that 55 cases out of 106 showed aberrant expression. The role of $\beta$-catenin is to regulate the cadherin-mediated intercellular adhesion. That explains the membranous expression of $\beta$-catenin. With the disruption of this function, cancer cells start to detach from primary nests and start invasion and metastasis. Under normal circumstances; in the absence of Wnt signaling, $\beta$-catenin is ubiquitinated and degrades by proteasomes [40]. However, many studies considered $\beta$-catenin as an oncogene whereby activating the Wnt signaling pathway, $\beta$-catenin is not phosphorylated and therefore accumulates in the cytoplasm. This leads to the translocation of $\beta$-catenin from the cytoplasm to the nucleus and hence regulating target genes like cyclin D1 and c-myc [41].

In this study, the aberrant expression of $\beta$-catenin was associated with advanced tumor grade, tumor stage, tumor diameter, muscle invasion, RFS and PFS and this supports the hypothesis that the activation of $\mathrm{Wnt} / \beta$-catenin pathway plays a role in the progression of cancer. This is like previous studies $[15$, $42,43]$ that indicated that the $\beta$-catenin expression is significantly associated with higher tumor grade, stage, and poor survival could be used as a predictor of the degree of transitional urothelial carcinoma. This study showed that $45.5 \%$ of cases with aberrant $\beta$-catenin expression showed positive AR expression while only $23.5 \%$ of the Aberrant $\beta$-catenin negative cases showed positive AR expression. This could be explained by the recent studies that found a relationship between Wnt/ $\beta$-catenin and androgen signaling. These studies revealed that both Wnt/ $\beta$-catenin and androgen pathways work separately in cells under normal circumstances. However, the situation is different in cancer; where $\beta$-catenin is associated with the development of androgen sensitivity and preferentially binds to AR to form $\beta$-catenin/AR com- plex which translocate to the nucleus $[11,12,13]$. In a study by Li et al. [41] concluded that androgen mediated AR signals appear to synergize $\beta$-catenin in the presence of androgens. Their conclusion depends on the finding that $\mathrm{AR}$ and $\beta$-catenin co-express in the urothelial carcinoma cell nuclei and form a complex with T-cell Factor. This factor is a co-factor of $\beta$-catenin and a downstream component of Wnt signaling in the presence of androgens.

Our study highlighted important information about the link between Wnt/ $\beta$-catenin and AR pathway during the progression of transitional urothelial carcinoma. Our study was unique because the study population was from a rural area with high incidence of bilharziasis. Our study also did not show any gender related association with $\mathrm{AR}$, which again, may be due to a difference in regional risk factors. We recommend that further studies should be done to examine the effect of hormone deprivation therapy and the expression of $\beta$-catenin.

\section{Conclusions}

The aberrant expression of $\beta$-catenin and AR positivity were both observed in higher tumor grade and muscle invasion. However, they are not related to the patient's gender. A link between Wnt/ $\beta$-catenin and AR pathway was observed in the study, where cases with aberrant $\beta$-catenin showed higher AR positivity. Aberrant $\beta$-catenin is related to RFS and PFS and this might be a useful marker for predicting the prognosis of urothelial carcinoma patients.

\section{The authors declare no conflict of interest}

\section{References}

1. Goebell PJ, Knowles MA. Bladder cancer or bladder cancers? Genetically distinct malignant conditions of the urothelium. Urol Oncol 2010; 28: 409-428.

2. Miyamoto H, Miller JS, Fajardo DA, et al. Non-invasive papillary urothelial neoplasms: the $2004 \mathrm{WHO} / \mathrm{ISUP}$ classification system. Pathol Int 2010; 60: 1-8.

3. Jemal A, Bray F, Center MM, et al. Global cancer statistics. CA Cancer J Clin 2011; 61: 69-90.

4. Siegel R, Naishadham D, Jemal A. Cancer statistics, 2013. CA Cancer J Clin 2013; 63: 11-30.

5. El-Sharkawi F, El Sabah M, Hassan Z, et al. The biochemical value of urinary metalloproteinases 3 and 9 in diagnosis and prognosis of bladder cancer in Egypt. J Biomed Sci 2014; 21: 72 .

6. 2004 hwneeCssrfN.

7. Hemelt M, Yamamoto $\mathrm{H}$, Cheng $\mathrm{KK}$, et al. The effect of smoking on the male excess of bladder cancer: a meta-analysis and geographical analyses. Int J Cancer 2009; 124: 412-419.

8. Miyazaki J, Nishiyama H. Epidemiology of urothelial carcinoma. Int J Urol 2017; 24: 730-734.

9. Hartge P, Harvey EB, Linehan WM, et al. Unexplained excess risk of bladder cancer in men. J Natl Cancer Inst 1990; 82: $1636-1640$ 
10. Rahman M, Miyamoto H, Chang C. Androgen receptor coregulators in prostate cancer: mechanisms and clinical implications. Clin Cancer Res 2004; 10: 2208-2219.

11. Wang G, Wang J, Sadar MD. Crosstalk between the androgen receptor and beta-catenin in castrate-resistant prostate cancer. Cancer Res 2008; 68: 9918-9927.

12. Schweizer L, Rizzo CA, Spires TE, et al. The androgen receptor can signal through Wnt/beta-Catenin in prostate cancer cells as an adaptation mechanism to castration levels of androgens. BMC Cell Biol 2008; 9: 4.

13. Jung SJ, Oh S, Lee GT, et al. Clinical Significance of Wnt/betaCatenin Signalling and Androgen Receptor Expression in Prostate Cancer. World J Mens Health 2013; 31: 36-46.

14. Bienz M, Clevers H. Linking colorectal cancer to Wnt signaling. Cell 2000; 103: 311-320.

15. Hu X, Ruan Y, Cheng F, et al. p130Cas, E-cadherin and beta-catenin in human transitional cell carcinoma of the bladder: expression and clinicopathological significance. Int J Urol 2011; 18: 630-637.

16. Urakami S, Shiina H, Enokida H, et al. Epigenetic inactivation of Wnt inhibitory factor-1 plays an important role in bladder cancer through aberrant canonical Wnt/beta-catenin signaling pathway. Clin Cancer Res 2006; 12: 383-391.

17. Hsu SM, Raine L, Fanger H. Use of avidin-biotin-peroxidase complex $(\mathrm{ABC})$ in immunoperoxidase techniques: a comparison between $\mathrm{ABC}$ and unlabeled antibody (PAP) procedures. J Histochem Cytochem 1981; 29: 577-580.

18. Bakry OA, Samaka RM, Shoeib MA, et al. Immunolocalization of androgen receptor and estrogen receptors in skin tags. Ultrastruct Pathol 2014; 38: 344-357.

19. Boorman GA. Animal model of human disease: carcinoma of the ureter and urinary bladder. Am J Pathol 1977; 88: 251-254.

20. Okajima E, Hiramatsu T, Iriya K, et al. Effects of sex hormones on development of urinary bladder tumours in rats induced by N-butyl-N-(4-hydroxybutyl) nitrosamine. Urol Res 1975; 3 : 73-79

21. McCahy PJ, Harris CA, Neal DE. The accuracy of recording of occupational history in patients with bladder cancer. Br J Urol 1997; 79: 91-93.

22. Birtle AJ, Freeman A, Munson P. The androgen receptor revisited in urothelial carcinoma. Histopathology 2004; 45: 98-99.

23. Boorjian S, Ugras S, Mongan NP, et al. Androgen receptor expression is inversely correlated with pathologic tumor stage in bladder cancer. Urology 2004; 64: 383-388.

24. Li Y, Izumi K, Miyamoto H. The role of the androgen receptor in the development and progression of bladder cancer. Jpn J Clin Oncol 2012; 42: 569-577.

25. Miyamoto H, Messing EM, Chang C. Androgen deprivation therapy for prostate cancer: current status and future prospects. Prostate 2004; 61: 332-353.

26. Chen F, Langenstroer P, Zhang G, et al Androgen dependent regulation of bacillus Calmette-Guerin induced interleukin-6 expression in human transitional carcinoma cell lines. J Urol 2003; 170: 2009-2013.

27. Mashhadi R, Pourmand G, Kosari F, et al. Role of steroid hormone receptors in formation and progression of bladder carcinoma: a case-control study. Urol J 2014; 11: 1968-1973.

28. Tuygun C, Kankaya D, Imamoglu A, et al. Sex-specific hormone receptors in urothelial carcinomas of the human urinary bladder: a comparative analysis of clinicopathological features and survival outcomes according to receptor expression. Urol Oncol 2011; 29: 43-51.

29. Ruizeveld de Winter JA, Trapman J, Vermey M, et al. Androgen receptor expression in human tissues: an immunohistochemical study. J Histochem Cytochem 1991; 39: 927-936.

30. Boorjian SA, Heemers HV, Frank I, et al. Expression and significance of androgen receptor coactivators in urothelial carcinoma of the bladder. Endocr Relat Cancer 2009; 16: 123-137.
31. Kauffman EC, Robinson BD, Downes MJ, et al. Role of androgen receptor and associated lysine-demethylase coregulators, LSD 1 and JMJD2A, in localized and advanced human bladder cancer. Mol Carcinog 2011; 50: 931-944.

32. Miyamoto H, Yao JL, Chaux A, et al. Expression of androgen and oestrogen receptors and its prognostic significance in urothelial neoplasm of the urinary bladder. BJU Int 2012; 109: 1716-1726

33. Kashiwagi E, Fujita K, Yamaguchi S, et al. Expression of steroid hormone receptors and its prognostic significance in urothelial carcinoma of the upper urinary tract. Cancer Biol Ther 2016; 17: 1188-1196.

34. Mir C, Shariat SF, van der Kwast TH, et al. Loss of androgen receptor expression is not associated with pathological stage, grade, gender or outcome in bladder cancer: a large multiinstitutional study. BJU Int 2011; 108: 24-30.

35. Zhuang YH, Blauer M, Tammela T, et al. Immunodetection of androgen receptor in human urinary bladder cancer. Histopathology 1997; 30: 556-562.

36. Miyamoto H, Yang Z, Chen YT, et al. Promotion of bladder cancer development and progression by androgen receptor signals. J Natl Cancer Inst 2007; 99: 558-568.

37. Noronha RF, Rao BR. Sex hormone receptors in localized and advanced transitional cell carcinoma of urinary tract in humans. Urology 1986; 28: 401-403.

38. Botelho MC, Machado JC, Brindley PJ, et al. Targeting molecular signaling pathways of Schistosoma haemotobium infection in bladder cancer. Virulence 2011; 2: 267-279.

39. Vale N, Gouveia MJ, Rinaldi G, et al. The role of estradiol metabolism in urogenital schistosomiasis-induced bladder cancer. Tumour Biol 2017; 39: 1010428317692247.

40. Stamos JL, Weis WI. The beta-catenin destruction complex. Cold Spring Harb Perspect Biol 2013; 5: a007898.

41. Gao C, Xiao G, Hu J. Regulation of Wnt/beta-catenin signaling by posttranslational modifications. Cell Biosci 2014; 4: 13.

42. Garcia del Muro X, Torregrosa A, Munoz J, et al. Prognostic value of the expression of E-cadherin and beta-catenin in bladder cancer. Eur J Cancer 2000; 36: 357-362.

43. Syrigos KN, Harrington K, Waxman J, et al. Altered gamma-catenin expression correlates with poor survival in patients with bladder cancer. J Urol 1998; 160: 1889-1893.

\section{Address for correspondence}

\section{Shaimaa Elzamly}

Pathology Department

Faculty of Medicine

Benha University, Egypt

e-mail: shaimaa.nagy1@gmail.com 